\title{
O crime socioambiental na bacia do rio Doce: uma crítica ao princípio de mercado
}

\author{
The socio-environmental crime in the doce river basin: a critical to \\ the market principle
}

\author{
Rosinei Ronconi Vieiras ${ }^{1}$ \\ Bruna Neitzel Sepulcri ${ }^{2}$ \\ Martha Tristão ${ }^{3}$
}

\begin{abstract}
Resumo
Este artigo discute o modelo desenvolvimentista e produtivista inserido nas sociedades contemporâneas, problematizando a própria noção de desenvolvimento presente hoje na maioria dessas sociedades. Procura fazer frente à tentativa de homogeneização dos modos de vida e à lógica exploratória e mercantilista de um sistema que tenta se impor e penetrar em todo o tecido social. Considera relevante potencializar outros modos de vida e relações que se contraponham ao modelo excludente e deteriorante, característico do sistema capitalista. Para tanto, envolve-se com a problemática exposta pelo maior crime socioambiental do Brasil, ocorrido na bacia hidrográfica do rio Doce, localizada nos Estados de Minas Gerais e do Espírito Santo.

Palavras-chave: Racionalidades. Crime ambiental. Desenvolvimentismo.
\end{abstract}

\begin{abstract}
The article discusses the developmental and productivist model inserted in the contemporary societies, questioning the very notion of development present today in the majority of these societies. It looks to face to the attempt of homogenization in the ways of life and the very exploratory and mercantilist logic of a system that seeks to impose and penetrate throughout the social composition of the society. It considers relevant to enhance other lifestyles and relationships that opposed to excluding deteriorating model present in the capitalist system. To this end, involved with the problems exposed by the biggest environmental crime of Brazil, occurred in the basin of Doce River, located in the States of Minas Gerais and Espírito Santo.
\end{abstract}

Keywords: Rationalities. Environmental crime. Developmentalism.

\footnotetext{
${ }^{1}$ Instituto Federal do Espírito Santo (IFES), Colatina, ES, Brasil. rosineirv@hotmail.com

${ }^{2}$ Universidade Federal do Espírito Santo (UFES), Vitória, ES, Brasil. bnsepulcri@hotmail.com

${ }^{3}$ Universidade Federal do Espírito Santo (UFES), Vitória, ES, Brasil. marthatristao@terra.com.br

Artigo recebido em: 01/06/2017. Aceito para publicação em: 29/08/2018.
} 


\section{Introdução}

O planeta Terra vive um período de intensas transformações técnico-científicas, em contrapartida das quais engendram-se fenômenos de desequilíbrios ecológicos que, se não forem remediados, no limite, ameaçam a vida em sua superfície [...] (GUATARRI, 2012, p. 7).

Embora a problemática mencionada pelo autor dessa epígrafe esteja muito influenciada pelo contexto pós-Guerra Fria, não seria nada estranho aproximá-la de nossa realidade. A busca desenfreada pelo lucro - sem se importar com os meios - é um transtorno para qualquer sociedade. No entanto, mais grave ainda se torna em regiões em que a prática da exploração - tanto de humanos quanto de demais seres - não se submete a nenhum rigor legal e/ou ético muito menos valoriza outra dimensão - que seja diferente daquela pautada pelos princípios do mercado.

Esse modus operandi, de grande parte das atividades econômicas, tem se constituído como uma ameaça à vida. Não são poucos os exemplos de morte e deterioração das condições de vida, para uma grande parte da população, que esse modelo de produção, subsumido às condições do mercado, tem proporcionado. Um recente exemplo dessa problemática é o crime socioambiental ocorrido na bacia hidrográfica do rio Doce, localizada na região Sudeste do Brasil, nos estados de Minas Gerais e Espírito Santo.

A população dos municípios banhados pelo rio principal dessa bacia, o Doce, vivenciou momentos de grande ansiedade, devido ao rompimento da barragem em Mariana, Minas Gerais. Por vários dias, outros municípios do entorno da bacia acompanharam pelas grandes mídias as notícias sobre esse desastre e suas implicações nas vidas dos moradores, até que, infelizmente, sentiram de perto os impactos que a lama trazia com sua chegada. Inicialmente foram jorrados cerca de 55 milhões de metros cúbicos de lama (DINIZ, 2015), no pequeno distrito de Santa Rita Durão. Esta lama, atravessando parcialmente o Estado de Minas Gerais, chegou ao Estado do 
Espírito Santo, onde atingiu o mar. A trajetória foi feita através do Rio Doce. Rio de extrema importância para as comunidades e municípios que dependem dele para exercer atividades econômicas, captar água e gerar energia. Por onde passou, a lama trouxe conflitos, causou mortes e deixou cidades inteiras sem captação de água para suprir as necessidades humanas básicas.

Tal fato provocou diferentes reações nos sujeitos envolvidos nessa tragédia. Desde alegações que, ancoradas no ideal da empregabilidade, demonstram uma aparente defesa em prol da empresa causadora da tragédia, até, predominantemente, atos e relatos de indignação por parte tanto da maioria dos atingidos como da sociedade em âmbito nacional e internacional.

Em face das afecções causadas por esse acontecimento e todo o intenso envolvimento vivenciado, nos sentimos impelidos e provocados a questionar a lógica/discurso e/ou racionalidade presente nesse fato mencionado.

Entendemos que a racionalidade estampada nessa tragédia não é nova, mas sim constituinte de um modelo econômico-financeiro já conhecido, estudado, criticado e, principalmente, abraçado por uma grande maioria de empresas - o capitalismo como modelo. Ressaltamos que não é proposta deste texto apresentar outros modelos ou mesmo elaborar novas críticas a esse sistema econômico, mas sim problematizar essa racionalidade em decorrência da capacidade que sua força agenciadora apresenta para se infiltrar nas subjetividades infrapessoais (LAZZARATO, 2014), apresentando-se como única possível, ocultando e invisibilizando outras formas de racionalidades.

No contexto apresentado, acreditamos que ao problematizar uma determinada realidade, estaremos, ao mesmo tempo, produzindo/criando espaços para outras lógicas possíveis. Nesse sentido, é interessante destacar a diferença entre um modelo que se beneficia de uma determinada 
"natureza" até o seu esgotamento, como tem sido o caso de muitas mineradoras, e outro em que a natureza, como fonte de renda, se estabelece em uma relação de cuidado, proteção e preservação, como no caso do turismo, uma das principais fontes de renda de alguns municípios do litoral do Estado do Espírito Santo.

Neste ensaio não pretendemos cair na retórica de demonizar uma determinada empresa esquecendo-nos de outros "personagens" participantes desse processo e do pensamento empresarial dominante, ou seja, da lógica ou discurso do mercado - referindo-nos a Foucault - que está, não somente por traz, mas ao lado, na frente e em toda volta. É a problematização dessa lógica e discurso que constitui a direção que pretendemos tomar. Como, também, problematizar a complexidade dos impactos desse crime socioambiental, trazendo as implicações resultantes dessa lógica/racionalidade e as tensões com outras diferentes formas de racionalidades e/ou pensamentos acerca dessa problemática. Além disso, buscamos contextualizar as influências da teoria pós-colonialista na constituição das relações sociais, culturais e ambientais, com o intuito de rever os pressupostos da racionalidade hegemônica determinista.

Conhecemos inúmeras tragédias socioambientais ocorridas pelo mundo em diferentes momentos da história. Relembrando algumas, destacamos o vazamento de petróleo no Golfo do México, provocado pela petrolífera inglesa BritshPetroleum (PB), em 2010; o naufrágeo do petroleiro grego Prestige, em 2002, ocasionando o vazamento de aproximadamente 10 milhões de litros de óleo no litoral da Galícia, na Espanha e o vazamento de óleo na Baía de Guanabara pela empresa brasileira Petrobrás, em 2000. Em praticamente todas, prevaleceu à lógica produtivista e de mercado, em detrimento do cuidado e compromisso ético com o ambiente. Também é muito comum, em casos envolvendo crimes/desastres socioambientais, a aplicação de multas. Mas muitas delas não são pagas, prescrevendo ou sendo revertidas em compensações ambientais, muitas vezes ineficientes. 
Isso demonstra o grau de importância com que são tratadas as questões relacionadas ao "meio ambiente".

Para este artigo, buscaremos em Stuart Hall, Boaventura de Sousa Santos e Edgar Morin alguns pressupostos teórico-epistemológicos para discutir aspectos da problemática em questão, como por exemplo, as noções de desenvolvimento, os aspectos socioculturais e a noção de natureza, a fim de contribuir para o entendimento, mesmo que inacabado, da racionalidade hegemônica, sua relação com o meio e a noção estabelecida acerca de desenvolvimento e progresso.

\section{A hegemonia produtivista-desenvolvimentista e suas implicações socioambientais}

O modelo econômico do Brasil e da maior parte dos países no mundo segue a lógica eficientista e produtivista. Modelo esse que acompanha boa parte das empresas que buscam competitividade no mundo globalizado. A ausência de relações éticas com o meio e com as diferentes formas de vida que nele se encontram constitui uma característica marcante e predominante desse modelo. Fato esse que não representa nenhuma novidade para o mundo dos "negócios". Inclusive a ideia de sustentabilidade adotada por muitas empresas precisa ser problematizada, uma vez que, na maioria das vezes tende a simplificar ações e ainda reduzir o meio ambiente a um mero provedor de recursos naturais ou mesmo banalizar o uso do termo sem nenhuma preocupação com seus princípios ou sua proposta éticofilosófica.

Essa busca desenfreada em ganhar mercado para obtenção de lucros sem limites ou quaisquer compromissos socioambientais sérios e comprometidos é responsável por uma série de consequências degradantes. O modelo e/ou racionalidade que se impregnou na cultura empresarial/econômica e tornou-se hegemônica tem como expoente o 
capitalismo, uma vez que "[...] o capitalismo, mais do que um modo de produção, é hoje um regime cultural e civilizacional [...]" (SANTOS e MENESES, 2010b, p.18).

A racionalidade moderna, bastante discutida por Boaventura de Sousa Santos, faz parte da tensão estabelecida entre os pilares da regulação e o da emancipação e também da apropriação e da violência (SANTOS e MENESES 2010b). O pilar da regulação, segundo o autor, é constituído pelos princípios do Estado, da Comunidade e do Mercado, enquanto o pilar da emancipação é constituído por três lógicas de racionalidades diferentes: a racionalidade estético-expressiva, a moral-prática e a cognitivoinstrumental.

Santos (2011) estabelece o conhecimento-emancipação como a trajetória progressiva entre o estado de ignorância (colonização) e um estado de saber (solidariedade). Enquanto considera o conhecimento-regulação como a trajetória entre um estado de ignorância (caos) e um estado de saber (ordem), ou seja, um conhecimento que progride do caos para a ordem.

Nessa forma de conhecimento, o que se procura é abolir ou negar o caos - algo que passa a ser revisto e questionável com as novas "descobertas" ou estudos -, como exemplifica Santos (2004) ao inferir as condições teóricas que provocaram a crise no paradigma dominante da modernidade, que seriam a "Teoria da Relatividade", de Albert Einstein; a mecânica quântica, de Heisenberg e Bohr; "A incompletude da matemática”, demonstrada por Gödel; e o "Princípio da Incerteza", de Heisenberg ou a "Ordem a partir da desordem", de Prigogine.

No entanto, devido às imposições e aos objetivos da racionalidade tecnocrata e científica, a lógica do conhecimento-regulação sobressaiu àquela do conhecimento-emancipação. Logo, "[...] a ordem transformou-se na forma hegemônica de saber e o caos na forma hegemônica de ignorância" (SANTOS, 2011, p. 79). A inversão desse princípio que consideramos, assim como o autor, necessário se fazer pode contribuir para abalar as estruturas 
hegemônicas da racionalidade instrumental e da utopia automática da tecnologia - a panaceia da tecnologia, como se essa fosse à solução única e possível para todos os problemas. Tal pensamento procura diminuir o poder da comunidade e a capacidade de avaliação do risco, transformando esse automatismo tecnológico em uma manifestação de suprema vontade (SANTOS, 2011).

Quanto à tensão entre a apropriação e a violência o autor vai dizer que, em geral, a apropriação baseia-se na incorporação e na assimilação do outro, ou seja, procura-se aproximação com o outro para lhe incorporar saberes hegemônicos, enquanto a violência vai anular culturas subalternas, provocando destruições físicas e humanas, sendo exercida por meio de proibições e da separação daquilo que é "certo" do que é "errado".

De acordo com Santos (2011), no domínio da regulação, o princípio da comunidade foi até o presente momento o mais negligenciado pelos princípios da modernidade ocidental, sendo quase totalmente tomado pelos objetivos do Estado e do mercado, todavia “[...] é o princípio menos obstruído por determinações e, portanto, o mais bem colocado para instaurar uma dialética positiva com o pilar da emancipação" (SANTOS, 2011, p. 75). Já no domínio da emancipação, de acordo com o referido autor, o princípio mais ignorado pela modernidade foi o da racionalidade estético-expressiva, resistindo a cooptação total, sendo mais resistente à colonização imposta pelo paradigma moderno.

O que percebemos é que essa tensão tem produzido forças com uma assimetria bastante desigual, sobressaindo-se o pilar do mercado e a racionalidade cognitivo-instrumental. Essas duas racionalidades possuem uma forte contribuição com as grandes atrocidades socioambientais que vêm ocorrendo nas últimas décadas e principalmente com a mais recente, ocorrida na bacia hidrográfica do rio Doce. A lógica dominante já se mostrou incapaz de resolver os problemas criados pela cientificidade moderna. Logo, 
acreditamos/apostamos que nas subalternidades existam possibilidades para apropriação do pensamento pós-abissal.

[...] o pensamento pós-abissal é um pensamento não-derivativo, envolve uma ruptura radical com as formas ocidentais modernas de pensamento e acção. No nosso tempo, pensar em termos nãoderivativos significa pensar a partir da perspectiva do outro lado da linha, precisamente por o outro lado da linha ser o domínio do impensável na modernidade ocidental. A emergência do ordenamento da apropriação/violência só poderá ser enfrentada se situarmos a nossa perspectiva epistemológica na experiência social do outro lado da linha, isto é, do Sul global não imperial, concebido como a metáfora do sofrimento humano sistémico e injusto provocado pelo capitalismo global e pelo colonialismo. $\mathrm{O}$ pensamento pós-abissal pode ser sumariado como um aprender com o Sul usando uma epistemologia do Sul (SANTOS, 2007, p. $22)$.

A crítica do autor à pretensão ocidental moderna de invisibilizar a diferença e as experiências sociais, que não partilham de seus pressupostos epistemológicos, vai ao encontro da problematização aqui realizada a respeito do predomínio de uma racionalidade cognitivo-instrumental, sobressaindo o pilar do mercado.

Podemos considerar que esse processo de invisibilização cumpriu, ao menos, uma dupla função, pois ao mesmo tempo em que procurou apagar ou reduzir a riqueza de experiências possíveis disseminou a crença de que não há alternativa possível, senão a do modelo econômico de mercado vigente.

No processo de "apagamento" de experiências, entendemos que muitos saberes e modos de vida, cuja importância para o contemporâneo ficou desconhecida, se perderam diante da imposição da lógica produtivista e mercadológica. Santos e Meneses (2010b) traz um exemplo emblemático do perigo da imposição de um conhecimento sobre outros, com base em hierarquias abstratas. O autor cita o caso desastroso em que a rizicultura milenar, com sistemas tradicionais baseados em conhecimentos hidrológicos e agrícolas ancestrais, praticada em uma ilha da Indonésia, foi substituída por sistemas científicos oriundos da revolução verde. O desastre dessa substituição levou à queda brusca da produtividade por repetidas vezes até o 
ponto de serem abandonados. O caso em questão evidencia o perigo da hierárquica arrogância epistemológica que negligencia outras experiências que não se pautem pelo seu rigor e à unilateralidade cientificista subordinada ao mercado que desvaloriza conhecimentos populares e mercantiliza bens de valores comuns.

A riqueza de experiências que se esquivam dessa lógica mercantilizada não é pequena. No caso da região hidrográfica do rio Doe, atingida pelos rejeitos de mineração, lembramos das diferentes experiências relatadas na "Carta Política da Caravana Territorial da Bacia do Rio Doce", em que são revelados outros modelos possíveis de desenvolvimento. Esses diferentes "modelos" estão representados por experiências agroecológicas, organizações comunitárias (pescadores, indígenas, dentre outros), agricultura familiar, artesãos etc. Todas essas experiências evidenciam a possibilidade real de outra lógica possível e/ou de outro processo cultural de relação como o espaço.

Nesse contexto, podemos destacar os agricultores ribeirinhos, situados à margem esquerda na localidade de Colatina, que há mais de 4 décadas desenvolvem uma relação intrínseca com o rio. Da terra e da água retiram diretamente o seu sustento e o de suas famílias. De certa maneira, o rio participa e até "dita" o tempo de plantar, uma vez que, ao ocupar com suas águas a margem de plantio, impede os agricultores de a utilizar. Lembramos ainda que, durante as cheias, o rio contribui com a fertilização do solo, reduzindo, assim, o custo do agricultor com adubação. Da mesma forma, os pescadores artesanais dos municípios atingidos ficaram impedidos de realizar suas atividades. Para eles, a lua, o vento e outros elementos "naturais" também, participam e informam o momento propício à pesca.

Os exemplos citados vão ao encontro de muitas outras experiências, que se constituem como formas/movimentos de resistências, protagonizados por vários povos da Terra. O mexicano Enrique Leff, ao pesquisar e estudar diferentes processos de (re)apropriação do espaço e caminhos para a 
sustentabilidade, realizado por diversos povos, entendeu que esses processos se constituem como movimentos socioambientais de "rexistência" (LEFF, 2016), pois tais movimentos não apenas resistem ao modelo dominante como também implicam outra forma de existência. O autor menciona o caso dos seringueiros no Brasil, as comunidades negras na Colômbia e as experiências de manejo comunitário dos bosques do México como modos sustentáveis de apropriação e/ou reapropriação da Natureza. Exemplos que caracterizam outra maneira de viver e conviver.

Esses e tantos outros fatos não relatados, além de representarem uma racionalidade não hegemônica, se constituem como modos de vida pautados em outra concepção de tempo que não o Cronos, aquele do relógio, mas sim algo mais próximo do Kairós, o tempo que altera o sentido daquilo que fazemos, tempo cuja natureza é qualitativa, de aproveitamento das oportunidades e paixão pelo que se faz.

É importante salientar que esses exemplos não devem ser tomados como modelos que substituirão algum outro já existente, mas como práticas contra hegemônicas que insinuam outra política da convivência com o espaço e seus elementos.

Cabe ainda destacar que embora a racionalidade estético-expressiva e o princípio da comunidade, discutidos por Santos (2007), tenham sido negligenciados pelo paradigma moderno, a riqueza de experiências é latente, assim como a pluralidade cultural e epistemológica. É nesse sentido que, embora a tentativa de homogeneização tenha sido objetivada pela lógica dominante, Hall (2014) chama a atenção para o aparecimento de novas identidades culturais, não fixas e em transição. Desse modo, se torna questionável a ideia de assimilação ou homogeneização cultural, afastandose, portanto, daquilo que Hall (2014) denomina de processo de tradução, ou seja, formações de identidades que atravessam fronteiras, carregando consigo tradições, linguagens, histórias coletivas e particulares pelas quais foram marcadas. 
Compreendendo a cultura como híbrida é possível subverter alguns binarismos como, colonizador/colonizado, dominador/dominado, conhecimento/ignorância e ainda a dominação do saber colonizador sobre o colonizado, vislumbrando um processo em movimento, descentrado e diaspórico, atravessado pelo espaço-tempo local e global.

Consideramos importante também ressaltar algumas características da colonização dos países latino-americanos, em que a conquista de terra se deu a partir da dominação de povos e de culturas e a exploração do meio ambiente garantiu a permanência dos colonizadores nos países colonizados. Lamentavelmente, "[...] a via para a nossa modernidade esta marcada pela conquista, expropriação, genocídio, escravidão, pelo sistema de engenho e pela longa tutela da dependência colonial" (HALL, 2003, p. 30).

Sabemos que povos e culturas foram marginalizados e, para Santos (2010a), assim como o selvagem (colonizado) representava um lugar de inferioridade, a natureza representou o lugar da exterioridade. Sendo exterior, não pertence. Não pertencendo, não é reconhecida. Portanto, é também inferior aos interesses próprios dos colonizadores.

O Selvagem e a natureza são de facto, as duas fazes do mesmo desígnio: domesticar a "natureza selvagem", convertendo-a num recurso natural. É essa vontade única de domesticar que torna a distinção entre recursos naturais e recursos humanos tão ambígua e frágil no século XVI como hoje (SANTOS, 2010a, p. 188).

Entretanto, mesmo que essa lógica exploratória e de dominação tenha se mantido, inferimos que não é unívoca. Outras formas de ser/estar no mundo se potencializam e as dicotômicas relações natureza $\mathrm{x}$ cultura, cultura x sociedade, colonizador x colonizado, economia x meio ambiente são questionadas. Esses diferentes modos/formas de viver e conviver são os responsáveis por ampliar a diversidade que estremece essa pseudohomogeneidade. É bem provável que neles estejam algumas pistas para as respostas aos diversos problemas - ambientais, sociais, culturais, políticos, econômicos etc. - existentes hoje em muitas sociedades, provocados ou 
produzidos, em parte, pelo paradigma das ciências modernas, que em sua arrogância e prepotência, ignorou as crenças, experiências e conhecimentos populares e do senso comum daqueles que viviam cotidianamente com o meio.

\section{Da produção de não-existências e invisibilização do outro à potencialização de outras racionalidades e modos de vida}

[...] O aumento dos níveis de vida pode estar ligado à degradação da qualidade de vida (MORIN; KERN, 1995, p. 92).

Designamos a diversidade epistemológica do mundo por epistemologias do Sul (SANTOS e MENESES, 2010b, p. 19).

Segundo Santos (2010a), a natureza foi uma das grandes descobertas do segundo milênio. Desde então foi transformada em provedora de recursos naturais, que deveriam ser explorados até à exaustão. Entretanto, essa exploração provocou a deterioração do meio ambiente, ascendendo diversos problemas socioambientais que não afetam da mesma maneira as diferentes comunidades e/ou populações existente.

Embora os efeitos de uma determinada agressão ecológica sejam tenham consequências bastante complexoas, a assimetria socioeconômica implicará em uma distribuição desigual dessesas efeitos. consequências. Seria simples dizer que todos sofrem as consequências. No entanto, uma análise mais crítica revelará que, dependendo do impacto, alguns estarão muito mais vulneráveis e sofrerão primeiramente e com maior intensidade os efeitos desse, com a provável concomitância da deterioração de suas vidas com as do ambiente biofísicosocial, pois “[...] a destruição da natureza acarreta a nossa própria destruição. Assim, a nossa subjetividade não se completa sem ela" (SANTOS, 2011, p. 81). Nesse caso, o autor chama a atenção para a constituição das subjetividades que vão além das identidades 
antropocêntricas, constituindo-se na reciprocidade entre todas as formas de vida e o ambiente.

$\mathrm{Na}$ esteira desse pensamento, Morin (2013) enriquece tal asserção ao assegurar que somos seres ecodependentes, ou seja, além da nossa identidade própria, que nos caracteriza, possuímos uma identidade de dependência ecológica. E é nessa relação ecológica que os indivíduos podem construir e manter sua existência, ou seja, "[...] a independência de um ser vivo requer sua dependência com relação a seu ambiente" (MORIN, 2013, p. 253).

Discutindo a ideia de que estamos vivenciando um momento de policrise em que há inter-retro-ações entre os diferentes problemas, o referido autor infere que esse seja um momento de agonia, pois

[...] se considerarmos enfim e sobretudo a situação atual de policrises enredadas e indissociáveis, então a crise planetária de uma humanidade ainda incapaz de se realizar enquanto humanidade pode ser chamada de agonia. Ou seja, um estado trágico e incerto em que os sintomas de morte e de nascimento lutam e se confundem [...] (MORIN; KERN, 1995, p. 102).

Nesse cenário, a realização da humanidade, enquanto humanidade, comporta toda a complexidade presente tanto no indivíduo quanto na sociedade, escapando de um transcendentalismo idealizado. A agonia, dentro desse aspecto, não pode ser entendida sob um único viés ou apenas e simplesmente como sintoma de morte, mas sim como via para uma transformação, como Morin e Kern (1995, p. 103) nos falam: “A agonia de morte/nascimento é talvez o caminho, com riscos infinitos, para a metamorfose geral... Com a condição de que venha a tomada de consciência, justamente, dessa agonia”.

A problemática da codependência e/ou inter-relação do ser vivo e seu meio expõe uma situação em que no mesmo espaço estão convivendo realidades de um e de outro lado de uma linha abissal, da qual fala Santos e Meneses (2010b). Sendo assim, todas as realidades que se situam do outro lado da linha são consideradas como inexistentes ou irrelevantes. Na melhor 
das hipóteses, desconsideradas em termos de experiências e conhecimentos. Por meio dessa divisão, acreditamos, assim como Santos e Meneses (2010b), que existem metaforicamente as epistemologias do Norte e as epistemologias do Sul. Aquelas se referindo ao conhecimento científico, tecnicista, calculável, que objetivam verdades unívocas e desclassificam conhecimentos do senso comum (monocultura dos saberes). Já as epistemologias do Sul representam a diversidade epistemológica do mundo (ecologia dos saberes), ou seja,

[...] parte do princípio que o mundo é epistemologicamente diverso e que essa diversidade, longe de ser algo negativo, representa um enorme enriquecimento das capacidades humanas para conferir inteligibilidade e intencionalidade às experiências sociais (SANTOS E MENESES, 2010b, p.18).

Ainda para o autor, o Sul representa o campo de desafios que procura reparar os danos causados no decorrer da história pelo capitalismo, em sua relação colonial com o mundo. Um colonialismo cujos danos podem ser observados tanto no campo biofísico-social quanto no do conhecimento, resultando em um epistemicídio, do qual nos fala Santos (2010a).

Antes de tomarmos emprestado, de Boaventura de Sousa Santos, a noção de monoculturas e ecologias, precisamos entender, ainda que superficialmente, a proposta crítica do autor a respeito da tensão entre a razão cosmopolita e a razão indolente. A razão cosmopolita, de acordo com Santos (2010a), parte do princípio de que o mundo é muito mais diverso do que a compreensão ocidental de mundo; reconhece que qualquer compreensão do mundo é importante, mas todas são parciais e limitadas; apresenta como característica a contração do presente e a expansão do futuro, que torna o presente apenas um instante momentâneo entre o passado e o futuro. Logo, a razão cosmopolita propõe a expansão do presente e a contração do futuro, pretendendo criar espaços-tempos indispensáveis para conhecer e valorizar as incontáveis experiências sociais que são vividas cotidianamente, evitando assim os desperdícios dessas experiências. 
Diferente da razão cosmopolita, a razão indolente corresponde aquela que provoca o desperdício de experiências, invisibilizando a riqueza de experiências possíveis existentes no mundo. Isso ocorre por meio de duas formas principais: a razão metonímica e a razão proléptica (SANTOS, 2010a). Em suma, a razão metonímica se reconhece como a única forma de racionalidade possível e, obcecada pela ideia de totalidade, concebe a primazia do todo sobre as partes que o compõem. Nessa razão, as partes não têm existência fora da relação com a totalidade, sendo que as possíveis variações do movimento das partes, vistas como particularidades, não afetam o todo (SANTOS, 2010a). Já a razão proléptica pensa o futuro concebendo-o como linear e fruto de um progresso. Essa ideia está embasada na monocultura do tempo linear que provoca a contração do presente e a dilatação do futuro para onde são projetadas todas as expectativas.

Explorando a ampliação das concepções de mundo, de cultura e de tempo, Santos (2010a) designa a sociologia das ausências para substituir a predominância da razão metonímica. "O objectivo da sociologia das ausências é transformar objectivos impossíveis em possíveis e com base neles transformar as ausências em presenças" (SANTOS, 2010a, p. 102). São várias as formas de produção de não-existências, variando de acordo com lógicas e processos pelos quais a razão metonímica vai produzir o "invisível".

Todas as vezes que alguma forma de vida, de cultura, de ser e agir são desqualificados ou rejeitados por serem ininteligíveis, sob o ponto de vista de determinadas óticas, produz-se inexistência. Perceba que se produz inexistências simplesmente por não reconhecer o Outro como legítimo, por não desafiar a razão indolente que vem sendo considerada a única lógica possível.

Por intermédio da crítica à razão metonímica, Santos (2010a) elenca cinco modos ou lógicas de promover não-existências: a monocultura do saber, em que a ciência moderna acredita ser a detentora dos saberes da altocultura; a monocultura do tempo linear, que transmite a sensação de que a 
história tem sempre o fim conhecido, como se o futuro fosse linear e sempre glorioso; a monocultura da naturalização das diferenças, que consiste em distribuir as populações por categorias, que justificam hierarquias; a monocultura da universalidade, que define padrões/escalas que servem para determinar a relevância ou irrelevância de outras formas de existir; e, por último, a monocultura da produtividade, em que o crescimento econômico é um objetivo inquestionável. Esse critério, nos alerta o autor, serve tanto para a natureza como ao trabalho humano.

Para cada uma dessas monoculturas, Santos (2010a) vai propor sua substituição por uma das cinco ecologias que apresentam, justamente, outras propostas em relação às monoculturas, tendo como princípio comum o reconhecimento de que a realidade não pode ser reduzida ao que existe (SANTOS, 2010a), são elas: a ecologia dos saberes; a ecologia das temporalidades; a ecologia dos reconhecimentos; a ecologia das transescalas; e a ecologia das produtividades.

Essas formas de não-existências são potentes para criticar a produção social das ausências. Entretanto, para esse ensaio, destacamos duas: a monocultura dos saberes e a monocultura da produtividade. Primeiro, percebam que os desastres/crimes socioambientais que afetam diversos municípios/comunidades pelo mundo a fora são fruto da onda desenvolvimentista e da lógica produtivista hegemônica, que estabelecem o progresso a partir do princípio de mercado.

No sentido exposto, Morin e Kern nos lembram que,

A Europa havia espalhado a fé no progresso pelo Planeta inteiro.
As sociedades, arrancadas a suas tradições, iluminavam o seu
devir não mais seguindo a lição do passado, mas indo em direção a
um futuro promissor e prometido [...] o progresso era identificado
com a própria marcha da história humana e impulsionado pelos
desenvolvimentos da ciência, da técnica, da razão [...] A fé moderna
no desenvolvimento, no progresso e no futuro havia se espalhado
pela Terra inteira [...] (MORIN; KERN 1995, p. 79).

Nessa perspectiva, “[...] a natureza produtiva é a natureza maximamente fértil num dado ciclo de produção [...]. Segundo essa lógica, a 
não-existência é produzida sobre a forma do improdutivo que, aplicada à natureza, é esterilidade [...]" (SANTOS, 2010a, p. 104). Ampliando a crítica, ressaltamos a seguinte inferência:

\begin{abstract}
A ideia desenvolvimentista foi e é cega às riquezas culturais das sociedades arcaicas ou tradicionais que só foram vistas através das lentes economistas e quantitativas. Ela reconheceu nessas culturas apenas ideias falsas, ignorância, superstições, sem imaginar que continham intuições profundas, saberes milenarmente acumulados, sabedorias de vida e valores éticos atrofiados entre nós [...] (MORIN; KERN, 1995, p. 84).
\end{abstract}

É emblemático o comentário que Morin e Kern (1995) realizam quando lembra que a ideia desenvolvimentista foi e é cega às riquezas culturais das sociedades tradicionais. Segundo o autor, essas comunidades só são vistas por meio das lentes quantitativas que, quando não apropriadas à sua lógica, podem ser deslocadas. Nas lentes quantitativas predomina a lógica de mercado, pela qual se acredita que tudo tem preço. Tal fato nos provoca a pensar: como mensurar a perda de uma vida causada por um crime/desastre socioambiental? Como calcular a perda das relações afetivas com o espaço no qual se relaciona e vive?

Nesse sentido, consideramos que esse de tal cegueira corresponde a um processo de invisibilização é, determinado produzido pelas epistemologias do Norte. Já a monocultura da produtividade contribuiu com a percepção e levou ao reconhecimento da lógica desenvolvimentista de mercado como único caminho possível. Dessa forma, Nesses termos, Santos (2010a, p. 104) lembra que "[...] o crescimento econômico é um objetivo racional inquestionável [...]", sendo, geralmente, a única racionalidade levada em consideração quando se propõe o investimento em cidades brasileiras, transformando essa lógica "[...] em critérios únicos de verdade e de qualidade estética [...]" (SANTOS, 2010a, p.102).

Para tornar-se inquestionável, tal lógica/racionalidade precisou entranhar-se em nossa subjetividade e cultura, por meio de uma série de mecanismo, dentre esses os discursivos e midiáticos. Concomitante a esse 
processo, podemos considerar a cooptação do Estado pelo aparato técnicofinanceiro das grandes corporações e o seu enfraquecimento na capacidade, tanto de agir e investir quanto de regular e coibir os abusos dessas grandes corporações.

Tomando como exemplo o crime socioambiental ocorrido em Minas Gerais, assistimos, em rede nacional, às diversas narrativas de "autoridades" políticas, expressando a preocupação e o medo do desemprego, bem como, a queda na arrecadação de impostos e da renda. Independentemente da veracidade de tais narrativas políticas, acreditamos que essas podem contribuir para enfraquecer os mecanismos regulatórios e sua capacidade de minimizar os impactos de um grande complexo industrial. Dessa maneira, pensamos que tais discursos empoderam esses complexos e legitimam uma ideia desenvolvimentista descomprometida com as dimensões socioambientais.

Essas narrativas políticas ganham ênfase pelo fato de que a empresa responsável pelo acidente emprega a maioria dos habitantes da localidade, bem como é responsável por $80 \%$ das arrecadações diretas e indiretas do município (TRIBUNA, 2015). Diante dessas afirmações, podemos questionar: como vivia a população daquele local antes da chegada dessa empresa? Afinal, estamos falando de um município histórico. Mariana foi a primeira vila, a primeira capital, a sede do primeiro bispado e a primeira cidade a ser projetada em Minas Gerais (PMM, 2016). Mariana é detentora de relíquias e casarios coloniais que contam parte da história do país. De acordo com o site daquela prefeitura, no município nasceram personagens representativos da cultura brasileira, dentre eles o poeta e inconfidente Cláudio Manuel da Costa, o pintor sacro Manuel da Costa Ataíde e o Frei Santa Rita Durão, autor do poema "Caramuru". Fácil perceber que o município não surgiu a partir da instalação de uma determinada empresa. Há muito estava formado. Aliás, os minerais explorados pelas 
multinacionais estiveram lá desde sempre. Entretanto, foram transformados em recursos econômicos por algumas multinacionais.

Nessa problematização, também consideramos pertinente trazer à baila as provocadoras ideias de Edgar Morin, quanto à noção de desenvolvimento. Segundo esse autor, esta não passa de uma noção pobre e abstrata e ao mesmo tempo subdesenvolvida. Percebemos que em nome de um suposto "desenvolvimento" nos afundamos em um mar de lama (literalmente), resultante de uma determinada "ordem" e um suposto "progresso" que foi estabelecido e, pelo que parece, não pretende se alterar, pelo menos pelas suas próprias conviç̧ões. Esse desenvolvimento não foi capaz de resolver os principais problemas do planeta, constituindo-se, portanto, como mito. Nas palavras de Morin e Kern (1995, p. 83), "O mito do desenvolvimento determinou a crença de que era preciso sacrificar tudo por ele. Permitiu justificar as ditaduras impiedosas, seja as de modelo 'socialista' (partido único), seja as de modelo pró-ocidental (ditadura militar)."

Podemos ainda estender essa ideia ao discurso presente na lógica de grande parte da economia capitalista de mercado, a qual percebe o lucro como um fim que justifica quaisquer meios. Nesse sentido, percebemos que a racionalidade corrente corresponde àquela em que, pelo "desenvolvimento" nos dias atuais, podemos entender como geração de empregos e pagamentos de impostos -, se justifica qualquer agressão socioambiental.

Outro ponto problemático é o papel da própria sociedade civil, organizada ou não, em todo esse processo de fortalecimento e/ou esfacelamento dessas lógicas ou racionalidades. Não pretendemos nos afastar, e nem seria possível, para realizar as problematizações, mas sim incluirmo-nos no conjunto dessa sociedade civil que, a nosso ver, tem papel fundamental em todo esse processo. Embora esse papel seja complexo, indefinido e antagônico, não podendo, portanto, ser definido de antemão qual e como será a sua contribuição ou direção, acreditamos que nessa 
sociedade civil está presente uma potência coletiva com forte capacidade mobilizadora, principalmente ativada, quando afetada de alguma forma.

Acreditamos que não somos somente o resultado dessa mesma sociedade que aí está e por isso reprodutores de sua lógica ou produtos dessa cultura. Antes, produtores de cultura, como Morin (1991, p. 21) observa, ao mencionar que "[...] a cultura gera os conhecimentos que regeneram a cultura. O conhecimento depende de múltiplas condições socioculturais, e, em retorno, condiciona essas condições".

No entanto, o mesmo autor, ampliando a discussão, lembra que não se pode ignorar que,

[...] toda cultura está vitalmente aberta ao seu mundo exterior, que é aí que vai buscar reconhecimento objectivos, e que há conhecimentos e ideais que migram de uma cultura para outra [...] e que a aquisição de uma informação, a descoberta de um saber, a invenção de uma ideia, podem modificar uma cultura, transformar uma sociedade, mudar o curso da história [...] (MORIN, 1991, p. $22)$.

É nessa abertura processual e flexível que se encontram as culturas com seus respectivos costumes e conhecimentos, que entendemos poder situar o espaço para mudança e possiblidades de existências e de outras relações. Acreditamos que diferentes sentidos e perspectivas podem surgir e ser impressos no espaço-tempo em que nos encontramos.

Nessas condições, os afetos causados atuam como dispositivos, com grande capacidade coletiva de alterações nos processos relacionais. Passageiros ou não, comportam potência de transformação tanto em determinadas estruturas quanto nos modos subjetivos de perceber o meio.

\section{Considerações Finais}

Entendemos que a complexidade que envolve as realidades trazidas nos limita quanto à apresentação de respostas exatas ou definitivas. Entretanto, procuramos trazer, mesmo reconhecendo a incompletude delas, 
algumas proposições, no sentido de insinuar saídas que impliquem em nos afastar dos processos de expropriação da vida e degradação de tudo aquilo de que ela é dependente.

A problematização em questão se dá sobre a forma como o modelo econômico capitalista entende e lida com as questões socioambientais. Em nossa concepção, tal forma tem se apresentado reducionista e exploratória/predatória. Defendemos que a dimensão socioambiental supera a ideia de meio ambiente, enquanto fornecedor de recursos para os meios de produção, e ultrapassa a lógica do desenvolvimento sustentável - cuja perspectiva tangencia muito mais para o desenvolvimentismo do que para a sustentabilidade. Para tanto, aproveitamos o triste ensejo do maior crime socioambiental do país para nos acompanhar durante as problematizações que propusemos.

Os impactos resultantes desse crime/desastre, considerado um dos maiores do mundo, são ainda de todo desconhecidos. As consequências foram muitas e variadas. Se por um lado, evidenciou a inescrupulosa relação da política com setores da mineração e as consequências para o ambiente, por outro provocou a mobilização de diferentes segmentos da sociedade civil, mostrando sua importância e protagonismo.

Em um primeiro instante, presenciamos/assistimos a diversas manifestações públicas ocorridas em âmbito local, nacional e até internacional. No entanto, suspeitamos que tais mobilizações perdem força a cada dia. Diante disso, questionamos se o que está ocorrendo é uma perda ou a transformação dos meios de luta e mobilização? Em que medida esse envolvimento da população afetada em tais processos de luta e mobilização tem modificado esse modelo explorador? Qual o potencial de transformação presente nesses processos e nas experiências de produção e de vida que foram trazidas ao longo do texto?

Embora consideremos que tais questões não possuem respostas prontas, procuramos, mesmo que minimamente, desenvolver algumas 
considerações a respeito dos questionamentos em questão, entendemos que os movimentos/mobilizações não são estáticos, mas que se transformam de acordo com os contextos. Percebemos que há uma perda nas forças de mobilização, decorrente em parte, da luta de contra poderes, no caso o enfrentamento com grandes corporações, inclusive, midiática.

Entretanto, entendemos também que, novos instrumentos, fruto inclusive das mobilizações e movimentos diversos ocorridos, se fazem presentes nessa nova configuração de luta. Exemplo disso é a entrada da esfera jurídica, por meio da Promotoria Pública, no cenário de disputa e consolidação de direitos e tentativas de ressarcimento dos danos socioambientais.

Diante desse contexto, inferimos que, embora a luta dos que se encontram atingidos por conta de um modelo, cuja lógica de mercado se faz presente de forma impositiva e predatória, seja bastante desigual, operar sob a ótica de diferentes forças se faz cada vez mais urgente e necessário. Seja por meio das mobilizações de rua, seja a partir da organização coletiva de diferentes segmentos sociais, seja na produção/criação de um texto, cada vez mais se torna imprescindível operar processos de luta e resistências das mais diferentes formas.

Tal processo é desiqual, visto qu o mercado tem ao seu lado diferentes poderes, entre eles, parte de um aparato técnico-midiático muito bem preparado, o que torna o desafio dos atingidos - incluindo aí os elementos não humanos - cada vez maior. No entanto, foram justamente essas minorias e a ameaça da ausência de um elemento não humano - nesse caso a água - que estremeceram algumas estruturas consolidadas da lógica de mercado. Nesse caso, nos referimos mais em nível local e regional, pois reconhecemos que, em nível global e até nacional, a estrutura mercadológica ainda impera, mesmo com a riqueza de novas experiências sendo cada vez mais potencializada. Se, em diferentes momentos, essa lógica foi priorizada frente às principais demandas que procederam, após esse crime 
socioambiental ocorrido em Mariana, percebemos também uma grande insatisfação com a continuidade desse modelo predatório e degradante.

Em diferentes momentos, pareceu ser mais urgente pensar em como retornar as atividades das empresas responsáveis do que promover um plano de recuperação socioambiental da Bacia Hidrográfica do Rio Doce e do litoral atingido. Diante disso, percebe-se qual a racionalidade se fez predominante. Nesse contexto, entendemos que uma alternativa propositiva corresponderia na capacidade de potencializarmos algumas das diferentes experiências apresentadas e/ou engendramos outras racionalidades que não estejam pautadas pela lógica do mercado, mas sim que priorizem a vida e valorizem os elementos responsáveis pela sua existência.

Lançando mão do pensamento de um dos autores que nos acompanhou, Santos (2011) lembra que, na tensão entre o princípio do mercado e o da comunidade, o primeiro sobressaiu em detrimento do segundo. Portanto, é na retomada e potencialização da solidariedade coletiva e participação política integrada, com fins comuns entre os membros de uma comunidade, que reside uma interessante alternativa à hegemonia perversa do mercado. Em suma, sabemos que nenhuma das questões levantadas possui respostas definitivas ou exatas, como também, as proposições expostas não representam um caminho de certezas. No entanto, acreditamos que o esforço coletivo para respondê-las se constitui como forma de confronto e resistência à lógica dominante e deteriorante que o mercado tem apresentado na contemporaneidade.

\section{Referências}

GUATARRI, Félix. As três ecologias. Tradução: Maria Cristina F. Bittencourt. Revisão da tradução Suely Rolnik. 21. ed. Campinas, SP: Papirus, 2012.

HALL, Stuart. A identidade cultural na pós-modernidade. 12. ed. Rio de Janeiro: Lamparina, 2014.

HALL, Stuart. Da diáspora: identidades e mediações culturais. Liv Sovik (org.). Tradução: Resende, Adelaine La Guardia, et al. Belo Horizonte: Editora UFMG, 2003. 
LAZZARATO, Maurízio. Signos, máquinas, subjetividades. Tradução: Paulo Domenech Oneto e Hortência Lencastre. 1. ed. São Paulo: Edições Sesc São Paulo; n 1, 2014.

LEFF, Enrique. A aposta pela vida: imaginação sociológica e imaginários sociais nos territórios ambientais do Sul. Prefácio de Leonardo Boff. Tradução: João Batpista Kreuch. Revisão técnica: Dr. Carlos Walter Porto-Gonçalves. Petrópolis, RJ: Vozes, 2016.

MORIN, Edgar. O método 1: a natureza da natureza. 3. ed. Porto Alegre: Sulina, 2013.

MORIN, Edgar. KERN, Anne Brigitte. Terra Pátria. Tradução: Paulo Azevedo Neves da Silva. Porto Alegre: Sulina, 1995.

MORIN, Edgar. O método IV: as ideias. Tradução: Emílio Campos Lima. Tradução portuguesa. Publicações Europa-América, Ltda. Editions du Seuil, 1991. Título original: La Méthode 4. Les Idées - Leur Habitat, Leur Vie, LeursMoeurs, Leur Organization.

PREFEITURA MUNCIPAL DE MARIANA (PMM). Conheça um pouco da história de Marina: a primeira cidade de Minas. Mariana, 2016. Disponível em: <http://www.pmmariana.com.br/historico>. Acesso em: 26 de nov. 2016.

SANTOS, Boaventura de Sousa. A crítica da razão indolente: contra o desperdício da experiência. 8. ed. São Paulo: Cortez, 2011.

SANTOS, Boaventura de Sousa. A gramática do tempo para uma nova cultura política. 3. ed. São Paulo: Cortez, 2010a.

SANTOS, Boaventura de Sousa; MENESES, Maria Paula (org.). Epistemologias do Sul. São Paulo: Cortez, 2010b.

SANTOS, Boaventura de Sousa. Para além do pensamento abissal: das linhas globais a uma ecologia de saberes. In: Revista Crítica de Ciências Sociais [Online], 78 | 2007, Disponível em: <http://www.scielo.br/scielo.php?script=sci_arttext\&pid=S010133002007000300004\&lng=en\&nrm=iso $>$. Acesso: 13 de Abr de 2017. http://dx.doi.org/10.1590/S0101-33002007000300004

SANTOS, Boaventura de Sousa. Um discurso sobre as ciências. 2. ed. São Paulo: Cortez, 2004. 